\title{
Optimal management of cytomegalovirus retinitis in patients with AIDS
}

This article was published in the following Dove Press journal:

Clinical Ophthalmology

6 April 2010

Number of times this article has been viewed

\author{
Michael W Stewart \\ Department of Ophthalmology, \\ Mayo School of Medicine, \\ Jacksonville, FL, USA
}

Correspondence: Michael W Stewart Department of Ophthalmology, Davis 2W, 4500 San Pablo Rd, Jacksonville, FL 32224, USA

$\mathrm{Tel}+$ I 904-953-2232

Fax + I 904-953-7040

Email stewart.michael@mayo.edu
Abstract: Cytomegalovirus (CMV) retinitis is the most common cause of vision loss in patients with acquired immunodeficiency syndrome (AIDS). CMV retinitis afflicted $25 \%$ to $42 \%$ of AIDS patients in the pre-highly active antiretroviral therapy (HAART) era, with most vision loss due to macula-involving retinitis or retinal detachment. The introduction of HAART significantly decreased the incidence and severity of CMV retinitis. Optimal treatment of CMV retinitis requires a thorough evaluation of the patient's immune status and an accurate classification of the retinal lesions. When retinitis is diagnosed, HAART therapy should be started or improved, and anti-CMV therapy with oral valganciclovir, intravenous ganciclovir, foscarnet, or cidofovir should be administered. Selected patients, especially those with zone 1 retinitis, may receive intravitreal drug injections or surgical implantation of a sustained-release ganciclovir reservoir. Effective anti-CMV therapy coupled with HAART significantly decreases the incidence of vision loss and improves patient survival. Immune recovery uveitis and retinal detachments are important causes of moderate to severe loss of vision. Compared with the early years of the AIDS epidemic, the treatment emphasis in the post-HAART era has changed from short-term control of retinitis to long-term preservation of vision. Developing countries face shortages of health care professionals and inadequate supplies of anti-CMV and anti-HIV medications. Intravitreal ganciclovir injections may be the most cost effective strategy to treat CMV retinitis in these areas.

Keywords: cytomegalovirus, AIDS, retinitis, immune recovery uveitis, retinal detachment, treatment

\section{Introduction}

Cytomegalovirus (CMV), a ubiquitous organism, is the largest of the herpes viruses. ${ }^{1}$ The prevalence of individuals with evidence of prior CMV infection varies by age, geographic region, and sexual history. Nearly $60 \%$ of individuals over the age of six years and more than $80 \%$ of those older than 80 years exhibit seropositivity. ${ }^{2}$ In men infected with human immunodeficiency virus-1 (HIV) and having a history of homosexual behavior, the prevalence of CMV seropositivity exceeds $90 \%$. $^{3}$

Healthy individuals infected with CMV frequently remain asymptomatic, although some develop an influenza-like syndrome characterized by fever, chills, malaise, myalgias, and arthralgias. People with normal immune systems rarely develop long-term sequelae. Similar to other herpes viruses, CMV then enters a latent state, continually suppressed by cell-mediated immunity. CMV remains latent unless the patient suffers from a significant local (regional corticosteroid therapy) or systemic 
immunodeficiency, acquired immunodeficiency syndrome (AIDS), pharmacologic immunosuppression to prevent allograft organ transplant rejection, local and systemic corticosteroid therapy, or an autoimmune condition such as Wegener's granulomatosis. Recurrent CMV infections may cause colitis, encephalitis, or retinitis (which account for $75 \%$ to $85 \%$ of CMV end-organ disease). ${ }^{4}$

The AIDS era began in 1981 when a group of five homosexual men developed unusual opportunistic infections (pneumocystis pneumonia, candidiasis, and CMV infections) due to severe immunodeficiency., 5 The ocular abnormalities in these patients included a non-infectious occlusive retinal microvasculopathy (Figure 1), and progressive, necrotizing retinitis (Figure 2 ). ${ }^{7}$

During the first 14 years of the AIDS era, retinal abnormalities were identified as the most significant ocular findings and the major cause of blindness in affected patients. Between $25 \%$ and $42 \%$ of AIDS patients developed CMV retinitis, the most common reason for severe vision loss. ${ }^{8-10}$ Retinitis occurred in advanced AIDS patients with $\mathrm{CD}^{+}$ T-lymphocyte counts of $<50$ cells $/ \mu \mathrm{L} .{ }^{11,12}$ Among patients with $\mathrm{CD}^{+} \mathrm{T}$-lymphocyte counts $<50$ cells $/ \mu \mathrm{L}$ the rate of $\mathrm{CMV}$ infection rate was 0.2 cases/person-year (PY). ${ }^{12}$

The introduction of highly active antiretroviral therapy (HAART) in 1996, originally defined as two nucleoside reverse transcriptase inhibitors (NRTIs) combined with a protease inhibitor (PI), and in 2004 expanded by the DHHS/Kaiser panel to include a PI, a non-nucleoside reverse transcriptase inhibitor, one of the NRTIs (abacavir or tenofovir), an integrase inhibitor (eg, raltegravir), or an entry inhibitor (eg, maraviroc or enfuvirtide), ${ }^{13}$ became a watershed event in the treatment of HIV-infected patients. HAART decreased the mortality rate among HIV-infected patients, and significantly decreased the incidence and altered the natural history of many opportunistic infections, particularly CMV retinitis. Although most large centers have observed an $80 \%$ decrease in the incidence of CMV retinitis, it remains the most common reason for vision loss in AIDS patients. ${ }^{14}$ The incidence of CMV retinitis in the post-HAART era is estimated to be at most 5.6 cases/100 PY. ${ }^{15}$

Despite the changes in incidence and severity of retinitis caused by HAART, the ophthalmoscopic appearance of CMV retinitis does not appear to have changed. The Longitudinal Study of the Ocular Complications of AIDS showed that the ocular findings in patients with newly diagnosed CMV retinitis in the post-HAART era resembled those prior to the introduction of HAART. ${ }^{16}$ However, differences in disease location, severity, and patient immune status have been reported.

On average, newly diagnosed CMV retinitis patients have $\mathrm{CD}^{+}$T-lymphocyte counts less than 50 cells/ $\mu \mathrm{L}$, but these values cover a broader range than in the pre-HAART era.

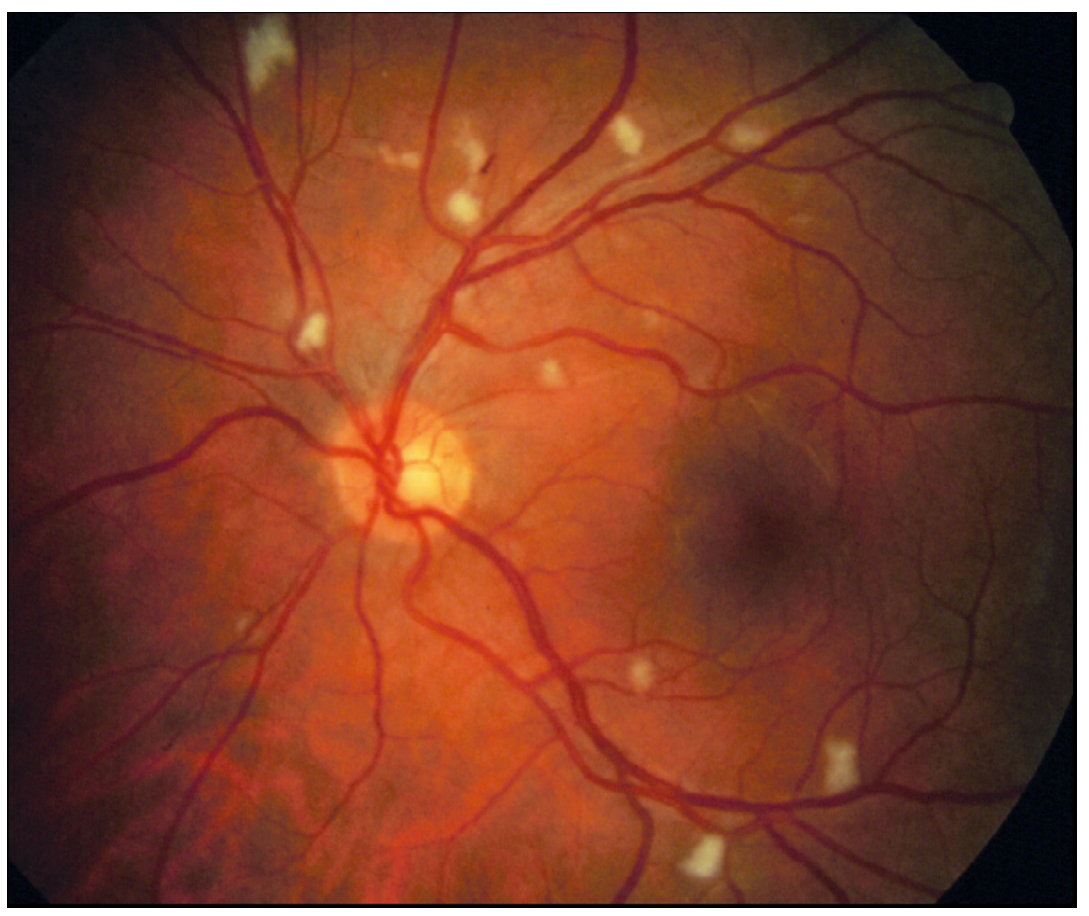

Figure I Numerous cotton wool spots typical of HIV retinopathy. 


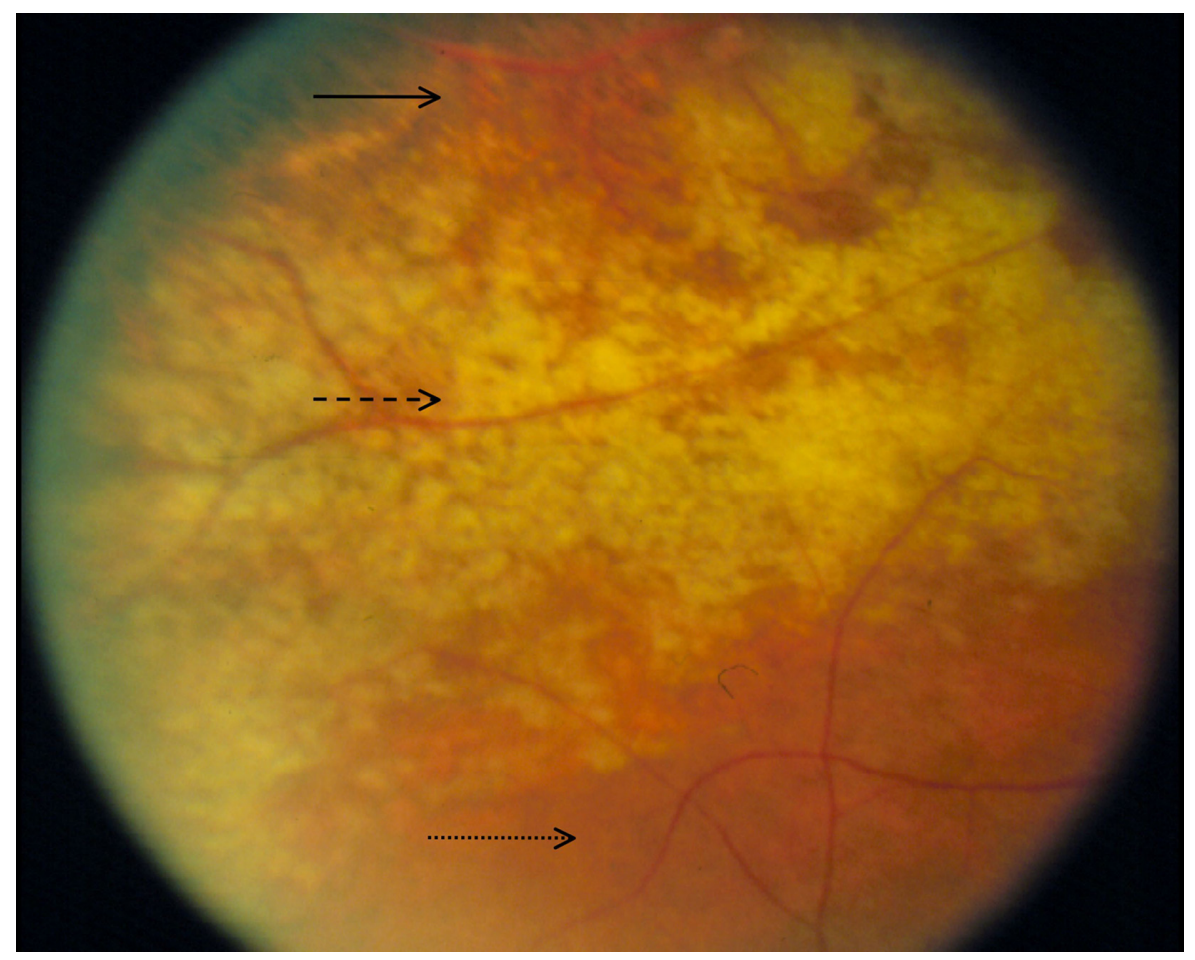

Figure 2 Retinitis is progressing from top to bottom: solid line points to area of necrotic retina following retinitis; dashed line points to area of active retinitis; dotted line points to area of normal retina.

This may indicate a selective loss of immunity against CMV not reflected by total CD4 $4^{+}$-lymphocyte count, or an improvement in laboratory values before the restoration of protective immunity. Up to $69 \%$ of newly diagnosed cases are due to HAART failure, as measured by either persistently low $\mathrm{CD} 4^{+} \mathrm{T}$-lymphocyte counts or high HIV RNA blood levels. ${ }^{17}$ Each of these factors independently predicts CMV reactivation. HAART failure patients more frequently present with asymptomatic, bilateral retinitis, better visual acuity, less zone 1 disease, and lesser lesion opacification. Since lesion opacification is believed to correlate with viral activity, these patients have lower levels of viral replication. ${ }^{18}$ Milder disease also correlates with better visual acuity and fewer symptoms. Since many patients have asymptomatic disease, physicians should consider regular ophthalmic screening examinations of at-risk patients.

Although the diagnosis of CMV retinitis indicates that these patients have HAART failure, the milder ocular disease suggests that HAART has a beneficial effect on modulating disease severity and vision loss. HAART-treated patients have a lower incidence of retinal detachment,${ }^{19}$ disease progression and second eye involvement. ${ }^{20}$ Despite this, HAART patients with CMV retinitis have an increased mortality rate, especially those with lower $\mathrm{CD} 4^{+} \mathrm{T}$-lymphocyte counts. ${ }^{21}$

\section{Intravenous therapy}

\section{Ganciclovir}

Ganciclovir (Cytovene ${ }^{\circledR}$, Roche Pharmaceuticals, Nutley, New Jersey, approved in 1989), the first anti-CMV drug, became available on a compassionate use basis in 1984. It is a synthetic acyclic nucleoside analog of $2^{\prime}$-deoxyguanosine. Following uptake by CMV-infected human cells, ganciclovir is monophosphorylated by the enzyme UL97 (the ratelimiting step) and then triphosphorylated to its active form by activated kinases of the host cell. The triphosphate form interrupts viral DNA synthesis by competing with deoxyguanosine triphosphate.

To achieve high tissue concentrations during induction, ganciclovir is administered twice daily at a dose of $5 \mathrm{mg} / \mathrm{kg}$. Since maintenance therapy is anticipated to continue for weeks to months in most patients, a peripherally-inserted central catheter (PIC) line is usually placed to allow atraumatic, repeated intravenous access. Catheter-related bacterial or fungal sepsis (occurring in $12 \%$ of patients) remains an important complication. ${ }^{22}$

Ganciclovir excretion occurs by glomerular filtration and active tubular excretion via the kidneys ${ }^{23}$ and is directly related to creatinine clearance. ${ }^{24,25}$ Patients with mild $\left(\mathrm{CL}_{\mathrm{CR}} \leq\right.$ $70 \mathrm{~mL} / \mathrm{min}$ ) to severe $\left(\mathrm{CL}_{\mathrm{CR}} \leq 10 \mathrm{~mL} / \mathrm{min}\right)$ renal impairment require lower ganciclovir doses because the areas under the 
curve are increased by 1.8 - to 15 -fold. Dose adjustments appropriate to renal function are given in Table 1.

Ganciclovir causes hematologic abnormalities (neutropenia, anemia, and thrombocytopenia) and probable long term reproductive toxicity. Women of reproductive age receiving ganciclovir need to be counseled about birth control. Patients with low neutrophil counts must discontinue ganciclovir or augment neutrophil synthesis with colony stimulating factors such as filgrastim (Neupogen ${ }^{\circledR}$ ). Weekly subcutaneous injections usually raise neutrophil counts to acceptable levels ( $>1000$ cells $/ \mathrm{mL})$. Since both ganciclovir and zidovudine are similarly capable of causing leukopenia, patients receiving both drugs frequently require reduced doses.

Viral resistance to ganciclovir occurs most commonly due to mutations in the viral protein kinase UL97 gene, which is responsible for monophosphorylation of ganciclovir. The incidence of viral resistance increases with the duration of therapy from $2.2 \%$ at three months to $15.3 \%$ at 18 months. ${ }^{26}$ Not surprisingly, viral resistance is associated with larger areas of retinitis and increased loss of vision. ${ }^{27}$

\section{Foscarnet}

Foscarnet (Foscavir ${ }^{\circledR}$, AstraZeneca LP, Wilmington, Delaware, approved in 1991) is a pyrophosphate analog. It interferes with the binding of the diphosphate to the viral DNA polymerase of Herpes simplex, Varicella zoster, cytomegalovirus, and HIV. ${ }^{28}$

Daily induction dosing of foscarnet consists of $180 \mathrm{mg} / \mathrm{kg}$ (usually given as $90 \mathrm{mg} / \mathrm{kg}$ twice daily) followed by maintenance therapy of $90 \mathrm{mg} / \mathrm{kg}$ once daily. Similar to ganciclovir, foscavir treatment usually lasts weeks to months, thereby requiring a PIC line.

Foscarnet is highly nephrotoxic and must be administered carefully to patients with renal disease. Patients require adequate hydration and frequent monitoring of creatinine levels. Viral resistance has been mapped to point mutations in the pol gene UL54. Cross-resistance between ganciclovir and foscarnet has been observed in numerous viral isolates with both phenotypic and genotypic resistance. ${ }^{28}$ Foscarnet is generally considered a second line therapy that is often administered to patients with ganciclovir-resistant viral strains or dose-limiting neutropenia. ${ }^{29}$

\section{Cidofovir}

Cidofovir (Vistide ${ }^{\circledR}$, Gilead Sciences, Inc., Foster City, California, approved in 1996) is an acyclic nucleoside phosphonate. Following intracellular phosphorylation to the diphosphate form by host kinases, cidofovir targets the viral DNA polymerase by acting as a chain terminator. After incorporation at the 3 '-end of the viral DNA chain, it terminates CMV DNA synthesis. Cidofovir is a broad spectrum antiviral agent with activity against CMV, acyclovir-resistant HSV infections, genital warts, laryngeal and cutaneous papillomatous lesions, molluscum contagiosum lesions, adenovirus infections, and progressive multifocal leukoencephalopathy (PML). ${ }^{30}$

The active form of cidofovir exhibits remarkable intracellular stability (half-life $>24$ hours) thus allowing for infrequent dosing. Induction dosing consists of $5 \mathrm{mg} / \mathrm{kg}$ once weekly for two weeks, followed by $5 \mathrm{mg} / \mathrm{kg}$ every other week during maintenance. Mutations of the viral DNA polymerase UL54 gene result in viral resistance to cidofovir as well as foscarnet and ganciclovir.

Severe renal toxicity is the major limitation to long-term cidofovir therapy. Patients must be adequately hydrated and pretreated with oral probenicid to protect against kidney failure. Due to the risk of renal toxicity and ocular hypotony, cidofovir is generally considered a second line therapy. Because of its association with immune recovery uveitis, cidofovir should not be used if immune recovery is expected.

\section{Oral therapy}

\section{Ganciclovir}

Oral ganciclovir was introduced in 1994 in an attempt to lower costs, eliminate the inconvenience of daily intravenous

Table I Recommended induction and maintenance dosing of IV ganciclovir adjusted for renal function ${ }^{63}$

\begin{tabular}{lllll}
\hline $\begin{array}{l}\text { Creatinine clearance } \\
(\mathbf{m L} / \mathbf{m i n})\end{array}$ & $\begin{array}{l}\text { Ganciclovir-IV induction } \\
\text { dose } \mathbf{( m g / k g )}\end{array}$ & Dosing interval (hours) & $\begin{array}{l}\text { Ganciclovlr-IV maintenance } \\
\text { dose } \mathbf{( m g / k g})\end{array}$ & $\begin{array}{l}\text { Dosing interval } \\
\text { (hours) }\end{array}$ \\
\hline$\geq 70$ & 5.0 & 12 & 5.0 & 24 \\
$50-69$ & 2.5 & 12 & 2.5 & 24 \\
$25-49$ & 2.5 & 24 & 1.25 & 24 \\
$10-24$ & 1.25 & 24 & 0.625 & 24 \\
$<10$ & 1.25 & 3 times per week, & 0.625 & 3 times per week, following \\
& & following hemodialysis & & hemodialysis \\
\hline
\end{tabular}


drug injections, reduce the risk of catheter-related sepsis, and improve patient quality of life. ${ }^{31}$ Maximum oral doses were $3 \mathrm{gm}$ per day (12 capsules taken on a three times daily schedule), but since the bioavailability was only $6 \%$ to $9 \%$, patients could not achieve plasma concentrations sufficient for induction therapy. ${ }^{22}$ The primary indication for oral ganciclovir was prevention of contralateral retinitis and non-ocular CMV disease in patients receiving intraocular therapy. ${ }^{32}$ When oral valganciclovir with its high bioavailability and convenient once-daily dosing was introduced, production and distribution of oral ganciclovir was discontinued.

\section{Valganciclovir}

Valganciclovir (Valcyte ${ }^{\circledR}$, Roche Pharmaceuticals, approved in 2000 ) is an orally administered monovalyl ester prodrug of ganciclovir. After absorption from the gut, valganciclovir undergoes rapid hydrolysis to ganciclovir in both the intestinal mucosa and liver. Ingesting valganciclovir with a high fat meal increases the area under the plasma concentration-time curve by $24 \%$ to $30 \%$, without prolonging the time to peak concentration. ${ }^{33}$

Because of its high bioavailability (60\%) valganciclovir can be used for both induction and maintenance therapy. ${ }^{34}$ Induction therapy, typically $900 \mathrm{mg}$ once daily for 2-3 weeks, results in serum ganciclovir levels 1.7 times those achievable with oral ganciclovir and comparable with those achieved with intravenous ganciclovir. Maintenance therapy is usually $450 \mathrm{mg}$ once daily. As with intravenous ganciclovir, dosing of valganciclovir should be decreased in patients with renal dysfunction (Table 2).

Oral valganciclovir is well tolerated, with the most common side effects being hematologic (neutropenia [16\%], anemia [11\%]), and gastrointestinal (diarrhea [13\%], nausea [8\%], and vomiting [4\%]). ${ }^{22}$ Drug interaction studies with valganciclovir have not been performed, but since it undergoes rapid conversion to ganciclovir, interactions are likely to be the same as with ganciclovir. Oral valganciclovir therapy is associated with a low incidence of viral resistance.

Table 2 Recommended induction and maintenance dosing of oral valganciclovir adjusted for renal function ${ }^{49}$

\begin{tabular}{lll}
\hline $\begin{array}{l}\text { Creatinine } \\
\text { clearance }(\mathbf{m L} / \mathbf{m i n})\end{array}$ & $\begin{array}{l}\text { Induction } \\
\text { dosage }(\mathbf{m g})\end{array}$ & $\begin{array}{l}\text { Maintenance } \\
\text { dosage }(\mathbf{m g})\end{array}$ \\
\hline$\geq 60$ & 900 BID & 900 QD \\
$40-59$ & 450 BID & 450 QD \\
$25-39$ & 450 QD & 450 every other day \\
$10-24$ & 450 every other day & 450 twice weekly \\
$<10$ & Not recommended & Not recommended \\
\hline
\end{tabular}

\section{Intravitreal therapy}

During the 1980s and 1990s intravitreal drug injections were given to patients who were intolerant of or refused systemic therapy. Several non-controlled studies show that most patients respond to induction therapy with each of the available drugs. Anti-CMV drugs can be injected in the office with topical anesthesia and sterile preparation of the eye with povidone-iodine solution (Figure 3). Although post-injection antibiotic drops have not been proven to lessen the incidence of endophthalmitis, most surgeons recommend broad spectrum treatment for 3-4 days.

Intravitreal injections of ganciclovir result in high retinal tissue concentrations without systemic bone marrow suppression. Since ganciclovir is supplied as a highly soluble powder, a wide range of concentrations can be formulated. Repeated doses ranging from $200 \mu \mathrm{g} / 0.1 \mathrm{~mL}$ to $2000 \mu \mathrm{g} / 0.1 \mathrm{~mL}$ have been injected into eyes without observable retinal toxicity. ${ }^{35,36}$ An accidently administered dose of $6 \mathrm{mg}$ caused no harm, but $40 \mathrm{mg}$ resulted in retinal damage. Twice-weekly injections are given during the induction phase, followed by weekly injections during maintenance. Time to disease progression has been estimated to be eight weeks. ${ }^{37}$

Few noncontrolled studies of intravitreal foscarnet injections have been published. ${ }^{38-40}$ In the largest series, 11 patients experienced successful induction therapy (six injections of $2400 \mu \mathrm{g}$ given at 72-hour intervals) followed by weekly maintenance injections. Reactivation of the retinitis occurred in $33.3 \%$ of patients within 20 weeks. Since foscarnet is distributed as a solution, higher drug concentrations cannot be made.

Cidofovir has a narrow therapeutic index for intravitreal injections, unlike ganciclovir which has a wide therapeutic index. Despite the manufacturer's warning against intravitreal administration, ${ }^{41}$ cidofovir has been injected into a small number of eyes. Cidofovir injections ( $20 \mu \mathrm{g}$ every 5-6 weeks) have been effective as induction therapy. With a mean followup of 15 weeks, $7.5 \%$ of patients (all previously treated with intravenous ganciclovir, foscarnet or both) experienced progression of their retinitis. Post-injection uveitis occurs frequently $(17 \% ; 41 \%$ in those not receiving prophylaxis with oral probenecid). Many patients experience a transient reduction in intraocular pressure and 3\% develop irreversible hypotony with severe vision loss. ${ }^{42}$ A double-masked, randomized trial of three cidofovir doses $(5 \mu \mathrm{g}, 10 \mu \mathrm{g}$, and $15 \mu \mathrm{g})$ was prematurely terminated due to high incidences of iritis (87\%) and hypotony (16\%), and low efficacy. ${ }^{43}$ Intravitreal administration of cidofovir is no longer recommended.

Fomiversin (Vitravene ${ }^{\circledR}$, Novartis Ophthalmics AG, Bulach, Switzerland, and Isis Pharmaceuticals, Inc, 


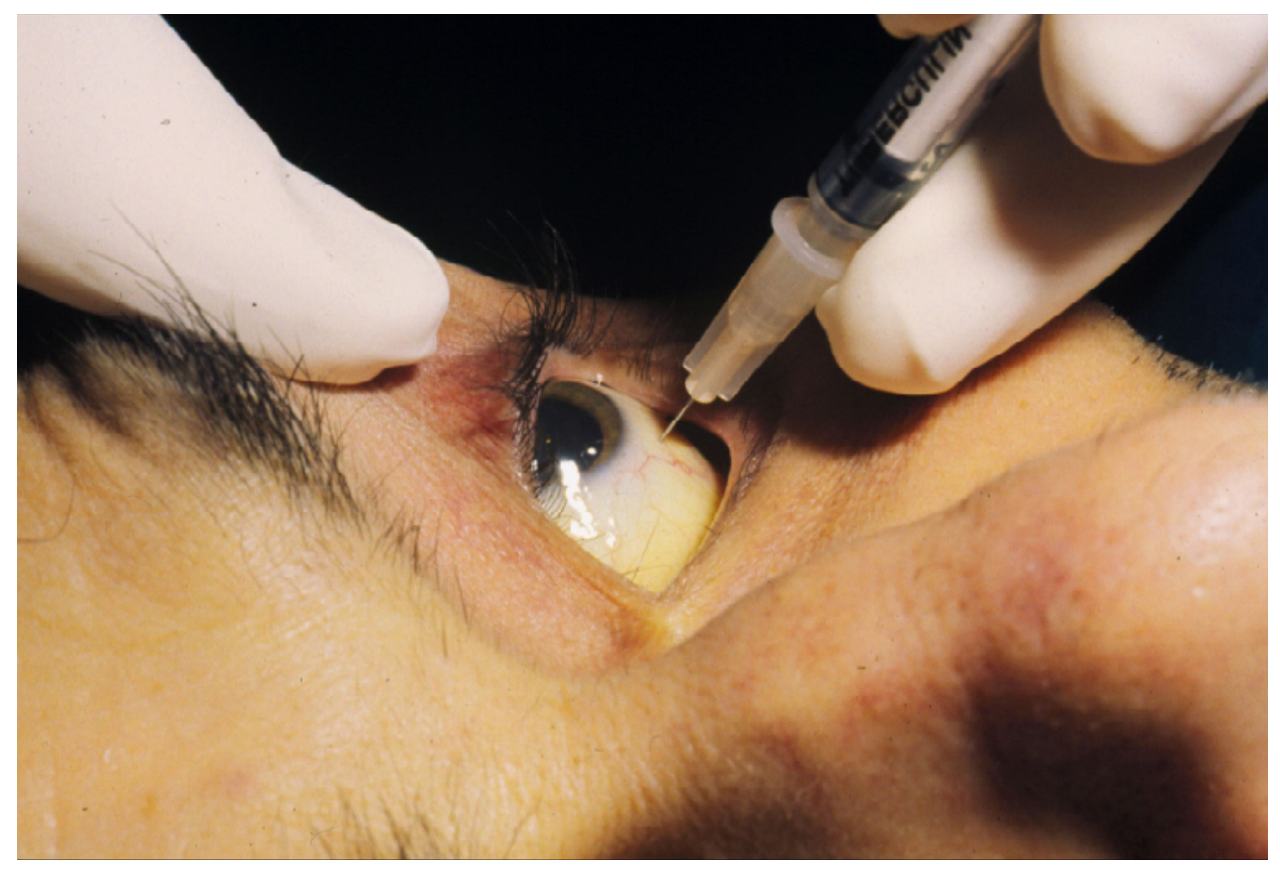

Figure 3 Intravitreal injection of ganciclovir through the pars plana.

Carlsbad, California, approved in 1998) is an antisense oligodeoxynucleotide that hybridizes with and blocks expression of CMV mRNA. Two intravitreal injections every other week were followed by monthly maintenance injections. The major complication was mild uveitis which was treated with topical corticosteroids. Production and distribution of fomivirsen has been discontinued.

The efficacy of intravitreal injections must be weighed against several inherent disadvantages. Weekly injections during the maintenance phase may be inconvenient for both the patient and physician. Although generally safe, intravitreal injections may be complicated by vitreous hemorrhages (3\%), retinal detachments $(8 \%)$, and endophthalmitis. Since CMV retinitis arises from active blood-borne disease, patients receiving intravitreal injections remain at risk for contralateral eye disease (11\%-30\%), non-ocular end-organ infections (16\%), and increased mortality. ${ }^{44-47}$ Most experts recommend that patients treated with intravitreal injections also receive systemic therapy with oral valganciclovir (most frequently) or one of the intravenous drugs.

\section{Ganciclovir implant}

The efficacy and safety of intraocular therapy, combined with the absence of systemic toxicity, spurred the development of the sustained-release ganciclovir implant $\left(\right.$ Vitrasert $^{\mathbb{}}$, Bausch and Lomb, Inc., San Dimas, California, approved in 1996). This polyvinyl alcohol/ethylene vinyl acetate device releases ganciclovir from a $4.5 \mathrm{mg}$ capsule at a rate of $1 \mu \mathrm{g} / \mathrm{hr}$ for up to nine months. In a randomized study, the implant extended the mean time to retinitis progression well beyond that achieved with intravenous therapy ( 221 days vs 76 days). ${ }^{48}$

The reservoir is surgically implanted through a pars plana incision and secured with a non-absorbable transscleral suture (Figure 4). A transient decrease in visual acuity occurs during the first two weeks following implantation. The risk of retinal detachment rises in the early post-operative period but decreases in the long term due to superior control of the retinitis. Since retinitis usually recurs when the ganciclovir implant empties, many surgeons either replace the implant after 32 weeks or, to avoid reopening the previous incisions, place an additional implant through a different pars plana site.

\section{Treatment strategies}

Improved patient survival with HAART has shifted the focus of anti-CMV treatment from short-term suppression of disease to long-term maintenance of vision. This means combining immune system reconstitution with effective short- or long-term anti-CMV therapy.

For patients not taking antiretroviral medications, one must first consider starting HAART; for HAART-failure patients, changing medications should be considered. Some infectious disease specialists will consider delaying HAART in patients with opportunistic infections to minimize the risk of immune recovery syndromes (immune recovery uveitis in patients with CMV retinitis). 


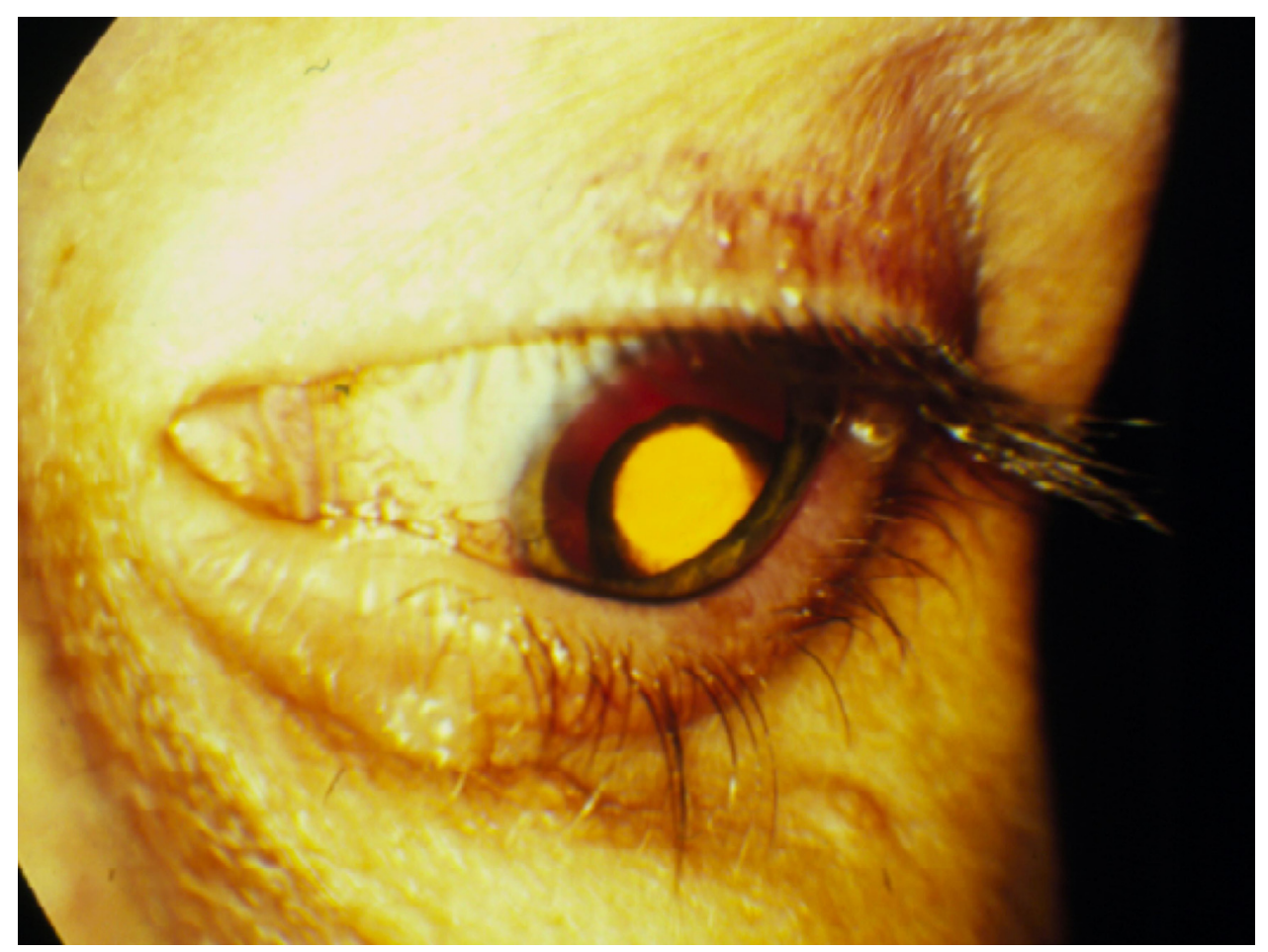

Figure 4 Sustained-release ganciclovir implant sutured to the pars plana as seen through the pupil.

Treatment of CMV retinitis should be individualized, taking into account the size and location of the retinitis, the patient's experience with HAART, and the risk of treatmentrelated complications. The location of infected retina determines the risk for vision loss; posterior retinitis threatens the macula and optic nerve; and anterior retinitis increases the risk of retinal detachment. The ocular fundus is divided into three zones; zone 1 encloses the area within $1500 \mu \mathrm{m}$ of the nerve or $3000 \mu \mathrm{m}$ of the fovea, zone 2 includes the area outside of zone 1 but posterior to the equator (as defined by the vortex veins), and zone 3 includes the peripheral retina between the equator and the ora serrata (Figure 5). ${ }^{8}$

Since CMV retinitis patients have a high risk of death that can be decreased by anti-CMV therapy, all patients, if possible, should receive systemic medication as part of the treatment regimen..$^{21,46}$

To suppress viral replication rapidly and minimize systemic complications (usually neutropenia and renal toxicity), early protocols developed the two-phase treatment strategy. A two- to three-week period of frequent, highdose drug administration to stop viral replication (induction phase) was followed by a continuous period of lower-dose therapy to suppress viral activity for as long as possible (maintenance phase). Induction therapy for CMV retinitis is usually with one of four available drugs, ie, ganciclovir, foscavir, cidofovir (all intravenous), oral valganciclovir, or surgical placement of the intravitreal ganciclovir implant. The choice of anti-CMV therapy is usually based on efficacy and tolerability profiles, pharmacologic considerations, and quality of life issues (Table 3). ${ }^{49}$ Comparison studies (intravenous ganciclovir with oral ganciclovir or intravenous foscarnet $t^{25,50,51}$ or cidofovir ${ }^{52}$ ) have failed to show significant differences between drug choices. Throughout the course of treatment, patients and physicians must remember that these drugs suppress CMV replication but do not eliminate the virus from the eye. Unless the patient experiences adequate reconstitution of the immune system, retinitis treatment must be continued indefinitely.

Episodes of relapse (also termed progression), defined as centrifugal advancement of the lesion borders, were expected with intravenous therapy. Early relapses were attributed to inadequate ocular drug concentrations, ${ }^{53,54}$ whereas later relapses were increasingly associated with acquired drug resistance. ${ }^{55-57}$ Unfortunately, the pace of relapses appeared to accelerate with the duration of treatment. Relapses were retreated with induction phase dosing, and this cycle was repeated until the patient's death. Except for therapy with the intravitreal ganciclovir implant, this strategy continues to be used.

For most patients, valganciclovir is the drug of choice, due to its lower cost and lower complication rate, as well as convenient oral administration. Induction therapy (900 mg 


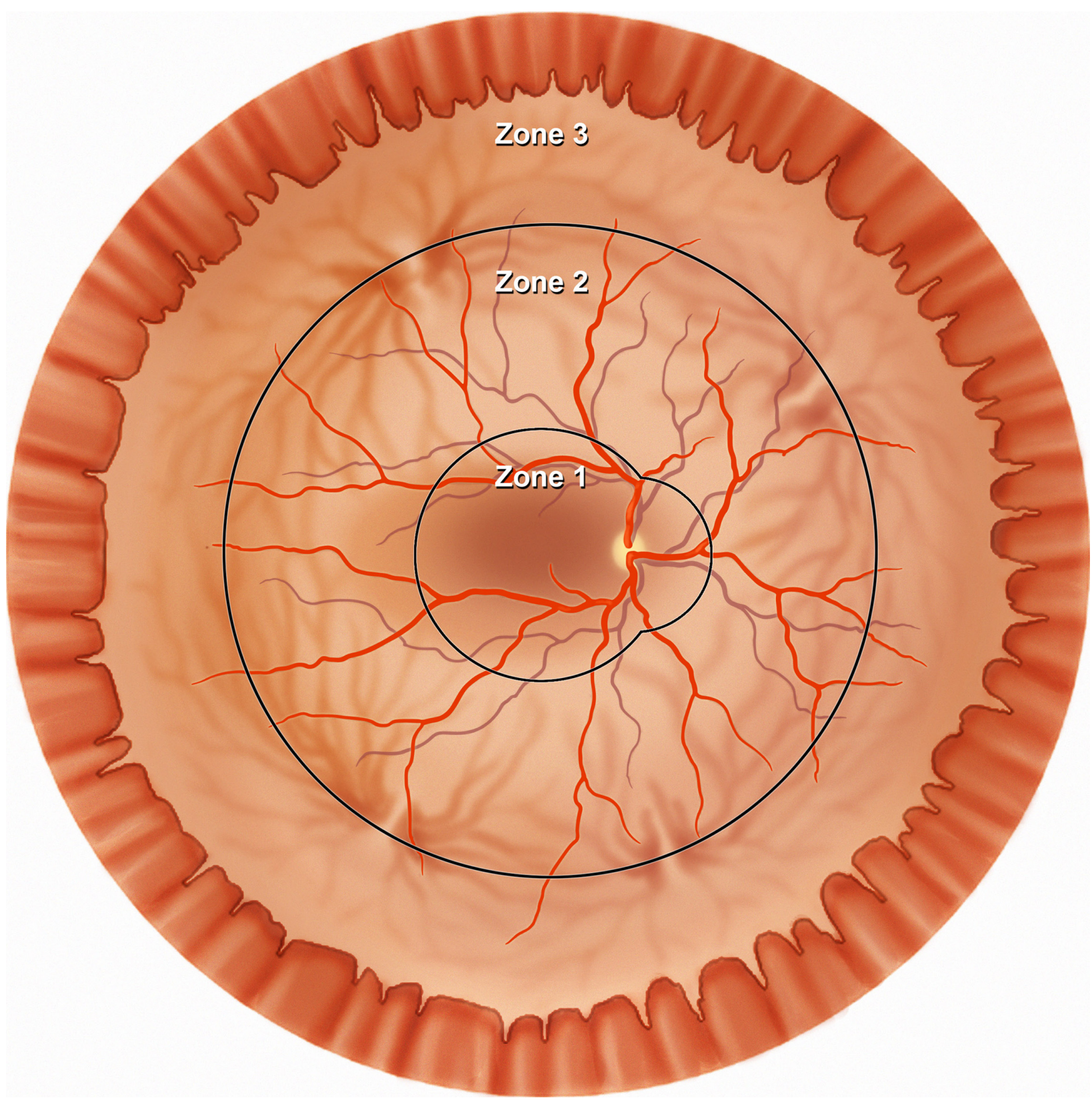

Figure 5 Diagram of the retina shows the three anatomic zones used for classification of CMV retinitis.

once daily) has been shown to be as effective as intravenous ganciclovir $\left(5 \mathrm{mg} / \mathrm{kg}\right.$ twice daily). ${ }^{58}$ This regimen arrests CMV progression in $>90 \%$ of eyes and achieves a satisfactory clinical response in $72 \%$ of patients. Median time to progression is 160 days, compared with 125 days in patients receiving intravenous ganciclovir induction therapy followed by oral ganciclovir maintenance. Among the $10 \%$ of patients who did not respond favorably to induction, $71 \%$ progressed within the first two weeks. The relative risk of progression in the valganciclovir group (compared with the ganciclovir group) was $0.9(95 \% \mathrm{CI}: 0.58,1.38)$. The incidence of retinal detachment was 19\% in each group. Systemic CMV suppression, as measured by serum, blood, and urine cultures, and PCR assay, occurred in both groups.

Each available anti-CMV drug regimen has associated disadvantages. Intravenous ganciclovir and foscarnet require indwelling catheters which increase cost, create inconvenience, and expose patients to the risk of secondary sepsis. Daily ganciclovir infusions last one hour, but each of three daily foscarnet infusions lasts two hours. The infrequent dosing of cidofovir does not require an indwelling catheter; however, the high risk of dose-related, potentially irreversible 
Table 3 Summary of dosing, adverse events, advantages and disadvantages of the available four systemic anti-CMV drugs ${ }^{49}$

\begin{tabular}{|c|c|c|c|c|}
\hline Feature & Ganciclovir & Foscarnet & Cidofovir & Valganciclovir \\
\hline Induction regimen & $\begin{array}{l}\text { IV: } 5 \mathrm{mg} / \mathrm{kg} \text { BID for } \\
2-3 \text { weeks Implant: } \\
4.5 \mathrm{mg} \mathrm{q} 5-8 \text { months }\end{array}$ & $\begin{array}{l}\text { IV: } 60 \mathrm{mg} / \mathrm{kg} \text { TID for } \\
2-3 \text { weeks }\end{array}$ & IV: $5 \mathrm{mg} / \mathrm{kg}$ qwk for $2 \mathrm{wk}$ & $\begin{array}{l}P O: 900 \mathrm{mg} \text { BID } \\
\text { for } 3 \mathrm{wk}\end{array}$ \\
\hline Maintenance regimen & $\begin{array}{l}\text { IV: } 5 \mathrm{mg} / \mathrm{kg} \text { QD } \\
\text { Implant: } 4.5 \mathrm{mg} \mathrm{q}^{5-8} \text { months }\end{array}$ & IV: $30-40 \mathrm{mg} / \mathrm{kg}$ TID & IV: $5 \mathrm{mg} / \mathrm{kg}$ q2 wk & PO: 900 mg QD \\
\hline Main adverse events & $\begin{array}{l}\text { IV: Bone marrow } \\
\text { suppression } \\
\text { Implant: post-operative ocular } \\
\text { complications }\end{array}$ & Nephrotoxicity & Nephrotoxicity and uveitis & $\begin{array}{l}\text { Bone marrow } \\
\text { suppression }\end{array}$ \\
\hline Advantages & $\begin{array}{l}\text { IV: systemic therapy Implant: } \\
\text { longest time to retinitis } \\
\text { progression in treated eye }\end{array}$ & $\begin{array}{l}\text { Systemic therapy; anti-HIV } \\
\text { activity }\end{array}$ & $\begin{array}{l}\text { Systemic therapy; least } \\
\text { expensive IV regimen; } \\
\text { infrequent dosing; no } \\
\text { indwelling venous catheter }\end{array}$ & $\begin{array}{l}\text { Systemic therapy; } \\
\text { convenient QD dosing; } \\
\text { low pill burden; no IV } \\
\text { catheter required }\end{array}$ \\
\hline Disadvantages & $\begin{array}{l}\text { IV: hematologic toxicity } \\
\text { Implant: requires } \\
\text { surgery; local effects only; } \\
\text { post-operative ocular } \\
\text { complications; expensive }\end{array}$ & $\begin{array}{l}\text { Nephrotoxicity; prolonged } \\
\text { daily infusions with } \\
\text { infusion pump }\end{array}$ & $\begin{array}{l}\text { Nephrotoxicity; requires } \\
\text { probenicid and hydration }\end{array}$ & Hematologic toxicity \\
\hline
\end{tabular}

nephrotoxicity (up to 50\%) requires pre-treatment with probenicid and adequate hydration. ${ }^{59}$ Nephrotoxicity and uveitis (seen in $10 \%$ of patients receiving the intravenous formulation) limit the use of cidofovir. ${ }^{60}$

The ganciclovir implant more effectively delays retinitis progression, but surgical implantation carries significant operative cost and comorbidities, such as endophthalmitis and retinal detachment. ${ }^{61}$ For HAART-naïve patients who may be expected to recover immunity against CMV, the eight months of continuous drug release may not be necessary. However, for patients with sight-threatening zone 1 retinitis, where rapid disease inactivation is critical to maintain vision, the implant, in combination with oral therapy, may be the best initial therapeutic choice (Table 4). ${ }^{32}$ While surgery is being planned, intravitreal injections of ganciclovir can quickly establish high intraocular antiviral levels to prevent disease progression. ${ }^{62}$ Since immune recovery is the most important factor for long-term CMV control, patients whose HAART therapy cannot be improved should be considered for implant surgery. Unless patients with the ganciclovir implant also receive systemic anti-CMV therapy, they are at high risk of developing both contralateral retinitis and extraocular CMV disease. Compared with intravenous therapy, oral valganciclovir equally prevents and treats non-ocular CMV disease. Valganciclovir has been shown to prevent the development of systemic CMV disease in $83 \%$ of patients and contralateral retinitis in $94 \%$ of cases. $^{22}$

The introduction of valganciclovir rapidly changed preferred treatment patterns. A retrospective analysis of insured patients in the US evaluated anti-CMV treatment from 1997 to 2002. The use of intraocular therapy changed minimally ( $13.3 \%$ to $15.8 \%$ ) whereas the use of oral drugs increased from $9.6 \%$ to $43.4 \%$, at the expense of intravenous therapy, which decreased from $77.1 \%$ to $40.8 \%$. This may be due in part to the lower cost of oral valganciclovir ( $\$ 69$ US/day vs $\$ 163 \mathrm{US} /$ day for the intravenous preparation). ${ }^{63}$

The rate of CMV reactivation has fallen from 3.0 cases/PY (pre-HAART) to 0.1 case/PY (post-HAART), with most of the improvement attributed to immune recovery. ${ }^{19}$ Reactivation of CMV retinitis can usually be successfully retreated with induction therapy and anecdotal reports suggest that repeat induction therapy in HAART-treated patients may require less aggressive therapy than in the pre-HAART era.$^{64}$ Recurrent disease always raises the concern of drug resistance, but the prevalence of drug-resistant CMV has fallen (from $28 \%$ to $9 \%$ ) since the introduction of HAART. ${ }^{65}$ Patients with drug-resistant infections can be difficult to treat and may require therapy with foscarnet or cidofovir.

Table 4 Suggested treatment strategy for patients with newly diagnosed CMV retinitis ${ }^{62}$

\begin{tabular}{lll}
\hline $\begin{array}{l}\text { CMV retinitis } \\
\text { location }\end{array}$ & $\begin{array}{l}\text { HAART } \\
\text { experienced }\end{array}$ & HAART naïve \\
\hline Zone I & $\begin{array}{l}\text { Ganciclovir implant }+ \\
\text { valganciclovir }\end{array}$ & $\begin{array}{l}\text { Ganciclovir implant + } \\
\text { valganciclovir }\end{array}$ \\
Zones 2 and 3 & $\begin{array}{l}\text { Valganciclovir } \pm \text { ganciclovir } \\
\text { implant }\end{array}$ & $\begin{array}{l}\text { Valganciclovir } \\
\end{array}$ \\
\hline
\end{tabular}


Reconstitution of the immune system following initiation of HAART can be sufficient to suppress CMV retinitis in some patients. More commonly, immune recovery allows for the discontinuation of anti-CMV therapy without rebound CMV reactivation in many patients. Long term studies show that patients with non-sight-threatening, quiescent retinitis for six months, and reconstitution of the immune system, may be considered for discontinuation of anti-CMV medications. The decision to stop CMV therapy depends upon many factors, including rising $\mathrm{CD} 4^{+} \mathrm{T}$-lymphocyte counts, falling systemic HIV loads (preferably to undetectable), duration of HAART (at least three months), and inactivity of CMV lesions. The US Centers for Disease Control (CDC) recommends that the $\mathrm{CD} 4^{+} \mathrm{T}$-lymphocyte be at least $100-150$ cells $/ \mu \mathrm{L}$ for $3-6$ months before CMV therapy is discontinued. ${ }^{66}$ However, most authors require more robust evidence of immune reconstitution (ie, CD4+ T-lymphocyte counts $>200$ cells $/ \mu \mathrm{L} ; 100$-fold drop in HIV blood levels) before discontinuing therapy ${ }^{67,68}$ Contradicting studies have reported successful discontinuation of therapy despite HIV blood levels exceeding 30,000 copies $/ \mathrm{mL}^{64}$

Once anti-CMV therapy has been discontinued, patients need close monitoring of their ophthalmologic status with attention to falling $\mathrm{CD}^{+} \mathrm{T}$-lymphocyte counts, and rising HIV blood loads. The risk of CMV reactivation is estimated to be 0.02 events/PY. ${ }^{64,68}$ Correlation exists between rising systemic CMV Ag titers and DNA levels, and reactivation of retinitis, but the predictive value of these tests remains insufficient to warrant routine screening. ${ }^{69}$ Serial ophthalmologic examinations at three-monthly intervals are frequently recommended, although supportive data for this practice does not exist. At-risk patients should be counseled to test themselves frequently for changes in visual acuity and peripheral fields; changes should be reported to their ophthalmologist immediately. Stopping anti-CMV therapy incurs reduced costs, decreased pill load, fewer complications, and better compliance with antiretroviral therapy.

Immune recovery many not occur for up to three months after institution of HAART, making patients susceptible to opportunistic infections (including CMV retinitis) during this period. An estimated $8 \%$ to $15 \%$ of CMV retinitis patients contracted their disease after apparently successful HAART-induced immune reconstitution. ${ }^{70}$ Generalized expansion of $\mathrm{CD}^{+} \mathrm{T}$-lymphocyte populations, but not the clones with specific anti-CMV memory, may allow retinitis to develop.

Pharmacologic prophylaxis against CMV disease in at-risk AIDS patients is clinically neither beneficial ${ }^{71}$ nor cost effective. ${ }^{72}$ A small study failed to prevent end-organ disease when anti-CMV therapy was given to HAART-treated patients with viremia (Wohl unpublished data 2006).

Unseen in the pre-HAART era, the immune-reconstitution inflammatory syndromes frequently complicate HAART therapy. Although these disorders have been given several names, immune reconstitution inflammatory syndrome (IRIS) has become the most widely accepted general term, ${ }^{73}$ with immune recovery uveitis (IRU) given to ocular inflammation. IRU occurs when the recovered immune system recognizes and then reacts to a large intraretinal CMV antigen load.

IRIS occurs in $15 \%$ to $25 \%$ of HIV-positive patients receiving HAART, with the highest incidence between eight and 16 weeks after initiation of treatment. ${ }^{74}$ Patients with low $\mathrm{CD}^{+} \mathrm{T}$-lymphocyte counts (fewer than 50 cells $/ \mu \mathrm{L}$ ), ${ }^{75}$ large areas of CMV retinitis (25\% to $30 \%$ of the retina) ${ }^{16}$ and a history of cidofovir use ${ }^{74}$ have the greatest risk of IRU. For patients who have had CMV retinitis, IRU occurs in $9.6 \%$ of those with immune recovery. ${ }^{16}$ The rate of visual impairment in HAART-treated patients is 0.1 cases/eye year (EY) and the rate of blindness is 0.06 cases/EY. The rate of visual impairment in IRU patients is 0.17 cases/EY. ${ }^{76}$ Although unusual, patients with partial immune reconstitution may develop IRU in the presence of persistent $\mathrm{CMV}$ retinitis. $^{70}$

Immune recovery uveitis usually coincides with a rapid reconstitution of the immune system, as measured by an increase in the $\mathrm{CD} 4^{+} \mathrm{T}$-lymphocyte count. A small percentage of patients, however, develop IRU without a $\mathrm{CD} 4^{+} \mathrm{T}$ lymphocyte increase, suggesting that improved immunity against CMV may occur by some as yet unrecognized mechanism. ${ }^{76,77}$ Affected patients have undetectable CMV DNA in blood and vitreous specimens. The clinical spectrum of IRU ranges from asymptomatic vitritis, through mild transient vitritis, to a persistent uveitis with floaters, decreased vision, cystoid macular edema $(12.3 \times$ increased risk $)$ and epiretinal membrane $\left(3.7 \times\right.$ increased risk) formation. ${ }^{78,79}$ Uveitis is believed to be directed toward residual CMV DNA at the edge of previous retinitis. ${ }^{80}$ Infrequent complications include neovascularization, disc edema, proliferative vitreoretinopathy, cataract and posterior synechiae. ${ }^{76}$ Although some patients experience severe vision loss (20/200 or worse), most patients have visual acuities between 20/50 and 20/200.

HAART-treated patients diagnosed with IRU need to have other inflammatory conditions (syphilis, herpetic retinitis, drug toxicity) excluded. PCR testing of intraocular fluids may help rule out infectious etiologies. ${ }^{81}$ 
In attempting to avoid IRU, some investigators recommend delaying HAART therapy until CMV retinitis is controlled. A small study reported a decreased rate of IRU when HAART was delayed until after induction therapy for CMV. This delay strategy carries significant risk given that infected patients have a high risk of death during the period immediately following diagnosis of CMV retinitis. ${ }^{82}$

Treatment of IRU depends upon the severity of the inflammation and the responsiveness of the complications. Mild inflammation with macular edema can sometimes be treated effectively with topical and periocular corticosteroids ${ }^{83,84}$ but other eyes are refractory to treatment. ${ }^{85}$ Intravitreal corticosteroids have successfully treated eyes refractory to less aggressive treatment but, in addition to the usual complications of cataracts and glaucoma, reactivation of retinitis may occur. ${ }^{85,86}$ The sustained-release intravitreal fluocinolone implant has successfully resolved inflammation and edema but has also caused reactivation of retinitis. ${ }^{87,88}$ To prevent CMV reactivation following corticosteroid treatment, some authors recommend restarting anti-CMV therapy. ${ }^{89}$ Surgery for cystoid macular edema, cataract, vitritis, and epiretinal membranes has yielded mixed results. ${ }^{87}$

Retinal detachments affected up to $40 \%$ of CMV-infected eyes $(0.5$ cases/PY) in the pre-HAART era. Post-HAART, the overall rate of detachment has fallen to 0.06 cases/PY, but remains high in patients with $\mathrm{CD}^{+} \mathrm{T}$-lymphocyte counts less than 50 cells $/ \mu \mathrm{L} .{ }^{19}$ Since many of these eyes had large areas of necrotic retina with persistent vitreoretinal traction, standard reattachment techniques (scleral buckle, vitrectomy with fluid/air exchange) were frequently unsuccessful. Vitrectomy with silicone oil tamponade quickly became the surgical procedure of choice. Despite successful reattachment, patients frequently lost vision due to cataract, aniseikonia, and for unknown reasons. Although silicone oil removal can improve visual acuity, it carries a $53 \%$ risk of retinal redetachment.

Now that patients are living much longer, and retinal detachment repair with silicone oil carries a poor visual prognosis, surgeons should consider attempting initial repair with air tamponade with or without scleral buckle. ${ }^{90}$ Patients for whom this approach is most appropriate may be those with peripheral disease for which posterior delimiting laser photocoagulation can be safely placed..$^{91}$

\section{CMV in developing countries}

The previous sections of this review discuss the optimal treatment of CMV retinitis while assuming that sufficient resources (HAART, anti-CMV drugs, health personnel, access to care) are available to affected patients. Although developed countries usually provide these resources, underdeveloped countries frequently lack one or more components. Consequently, patients may receive "substandard" care, with a higher likelihood of vision loss and decreased life expectancy.

At present $90 \%$ of HIV-infected people live in the developing countries of sub-Saharan Africa, the Indian subcontinent, Latin America, and Southeast Asia. Significant regional variability exists in the prevalence of opportunistic infections, with high rates of tuberculosis, cryptococcus and pneumocystis pneumonia.

An estimated $5 \%$ to $25 \%$ of AIDS patients in developing countries will develop blindness. ${ }^{92}$ The incidence of CMV retinitis in India varies from $2 \%$ in HAART-treated patients (with another $6 \%$ of patients developing IRU) $)^{93}$ to $20 \%(35 \%$ of which were active infection; 65\% were healed lesions), with the majority of these receiving HAART. ${ }^{94}$ Biswas et al reported that $17 \%$ of HAART-naïve patients had CMV retinitis ${ }^{95}$ and eight years later the same authors reported that the incidence had fallen to $5.7 \% .{ }^{96} \mathrm{Up}$ to $25 \%$ of patients with a history of CMV retinitis develop IRU. ${ }^{94}$

The incidence of CMV retinitis in sub-Saharan Africa varies from $0 \%$ to $19.6 \%{ }^{97-101}$ In Malawi the prevalence of anterior segment AIDS-related eye disease was 13\%, whereas retinitis was seen in only $1 \%$ of patients. ${ }^{102}$ None of 56 patients in a Gambian study had retinitis. ${ }^{103} \mathrm{CMV}$ retinitis developed in $0.2 \%$ of HAART-naïve patients in Ethiopia ${ }^{99}$ but $19.8 \%$ of HAART-treated patients in Thailand. ${ }^{101}$ The low prevalence of HIV-related eye disease in Africa may be due to patients dying before developing ocular opportunistic infections. ${ }^{92,104}$ The low incidences observed in Africa differ from those reported in India, suggesting that the diagnosis of retinitis may depend more upon access to medical care than on racial or geographic differences. ${ }^{105}$ Regional variations in the prevalence of opportunistic organisms and government-sponsored HAART distribution programs may also account for the lower incidence of CMV retinitis in some areas.

The experience at one Indian referral center illustrates the consequences of health funding shortfalls facing developing countries. Ten of 23 newly diagnosed CMV retinitis patients received two weeks of induction therapy (intravenous ganciclovir) followed by one week of maintenance. Limited resources prevented the continued administration of systemic maintenance therapy, but three patients received intravitreal ganciclovir injections. ${ }^{95}$ 
Indian cost and income data from 2000 illustrates the financial challenges in treating CMV retinitis patients: intravenous ganciclovir therapy costs \$714/month, antiHIV therapy costs $\$ 547 /$ month, with the average per capita income being only $\$ 380 /$ month. Working within these financial constraints, intravitreal ganciclovir injections emerge as the most cost-effective, available method of controlling $\mathrm{CMV}$ retinitis. Intravitreal ganciclovir injections have been successfully used at selected centers in South Africa, Botswana, ${ }^{97}$ and Thailand, ${ }^{101}$ and intravitreal foscarnet has been used for both induction and maintenance therapy. ${ }^{106}$ A Thai economic model suggested that CMV retinitis treatment with intravenous ganciclovir or oral valganciclovir would be cost-effective, whereas intravitreal ganciclovir injections would be cost-effective for patients not receiving HAART. ${ }^{107}$ Although injections fail to prevent non-ocular $\mathrm{CMV}$ infection and contralateral CMV retinitis, and may not extend life expectancy, they allow patients the opportunity to maintain useful vision.

Effective intravitreal therapy regimens require adequately trained ophthalmic professionals to perform early screening eye examinations, regular followup examinations and intravitreal injections. Unfortunately, many developing countries are deficient in trained ophthalmic personnel. Perhaps the challenges involved in treating CMV retinitis were best summarized by Shah: "The availability and cost of drugs such as ganciclovir and followup for ocular diseases such as CMV retinitis limit the visual outcome in these patients."

Many patients fail to return for followup examinations after being diagnosed with CMV retinitis. ${ }^{96}$ Although some authors recommend ophthalmic screenings of at-risk patients, ${ }^{108}$ limited resources make such programs difficult to implement. HIV-infected patients in India do not receive routine ophthalmologic examinations and are seen only if they become symptomatic. ${ }^{96}$ The incidence of CMV retinitis, particularly in patients with asymptomatic zone 3 disease, may be underestimated because of inadequate ophthalmic screening programs. Additionally, inadequate followup of patients with diagnosed CMV retinitis patients may doom them to blindness because of unchecked disease progression.

HAART generally decreases the incidence of CMV retinitis and, through reconstitution of the immune system, establishes long term remission. In developing countries this requires government and non-government agencies to provide medical care and anti-HIV medications at affordable prices. ${ }^{109}$ The governments of India and Thailand now provide anti-HIV medications free of charge to all infected patients. ${ }^{101,110}$ Increasing availability of HAART in countries such as India may change the incidence of CMV retinitis due to several factors, including longer survival, improved immunologic status, and increased incidence of immune recovery uveitis. ${ }^{93}$ However, despite the availability of HAART, AIDS patients in low-income countries have higher mortality rates than those in high-income countries. ${ }^{111}$

\section{Future}

Currently available anti-CMV drugs have unfavorable toxicity profiles, and foscarnet and cidofovir have insufficient bioavailability to be administered orally. A need remains for an effective oral agent with minimal toxicity.

The CMV epidemic associated with AIDS drove the development of anti-CMV medications during the $1980 \mathrm{~s}$ and $1990 \mathrm{~s}$ but the introduction of HAART, with the resultant dramatic decrease in CMV retinitis, served to slow drug development. However, during the same period, advances in organ procurement, surgical instrumentation and techniques, and anti-rejection drugs have enabled organ transplant programs to flourish. Organ recipients are at high risk of non-ocular CMV, which is now called the "troll" of organ transplant patients. Their need for chronic CMV suppression has served to re-stimulate drug development. Future drug development may, therefore, depend upon success in organ recipient trials.

\section{Disclosures}

The authors report no conflict of interest in this work.

\section{References}

1. Kedhar SR, Jabs DA. Cytomegalovirus retinitis in the era of highly active antiretroviral therapy. Herpes. 2007;14:66-71.

2. Staras SAS, Dollard SC, Radford KW, et al. Seroprevalence of cytomegalovirus infection in the United States, 1988-1994. Clin Infect Dis. 2006;43:1143-1151.

3. Drew WL, Mitz L, Miner RC, et al. Prevalence of cytomegalovirus infection in homosexual males. J Infect Dis. 1981;143:188-192.

4. Gallant JE, Moore RD, Richman DD, et al. Incidence and natural history of cytomegalovirus disease in patients with advanced human immunodeficiency virus disease treated with zidovudine. The Zidovudine Epidemiology Study Group. J Infect Dis. 1992;166:1223-1227.

5. Gottlieb MS, Schroff R, Schanker HM, et al. Pneumocystis carinii pneumonia and mucosal candidiasis in previously healthy homosexual men: Evidence of a new acquired cellular immunodeficiency. $\mathrm{N} \mathrm{Engl} \mathrm{J}$ Med. 1981;305:1425-1431.

6. Masur H, Michelis MA, Greene JB, et al. An outbreak of communityacquired Pneumocystis carinii pneumonia: Initial manifestation of cellular immune dysfunction. $N$ Engl J Med. 1981;305:1431-1438.

7. Holland GN, Gottlieb MS, Yee RD, et al. Ocular disorders associated with a new severe acquired cellular immunodeficiency syndrome. Am J Ophthalmol. 1982;93:393-402.

8. Holland GN, Buhles WC, Mastre B, Kaplan HJ. A controlled retrospective study of ganciclovir treatment for cytomegalovirus retinopathy. Use of a standardized system for the assessment of disease outcome. UCLA CMV Retinopathy Study Group. Arch Ophthalmol. 1989;107:1759-1766. 
9. Studies of Ocular Complications of AIDS Research Group in collaboration with the AIDS Clinical Trials Group. Foscarnet-Ganciclovir Cytomegalovirus Retinitis Trial: 5. Clinical features of cytomegalovirus retinitis at diagnosis. Am J Ophthalmol. 1997;124:141-157.

10. Bloom JN, Palestine AG. The diagnosis of cytomegalovirus retinitis. Ann Intern Med. 1988;109:963-969.

11. Kupperman BD, Petty JG, Richman DD, et al. Correlation between $\mathrm{CD} 4{ }^{+}$counts and prevalence of cytomegalovirus retinitis and human immunodeficiency virus-related noninfectious retinal vasculopathy in patients with acquired immunodeficiency syndrome. Am J Ophthalmol. 1993; 115:575-582.

12. Pertel P, Hirschtick RE, Phair J, et al. Risk of developing cytomegalovirus retinitis in persons infected with the human immunodeficiency virus. J Acquir Immune Defic Syndr. 1992;5:1069-1074.

13. Definition of HAART. Available from: http://statepiaps.jhsph.edu/wihs/ Invest-info/Def-haart.pdf. Accessed on January 10, 2010.

14. Skiest DJ. Cytomegalovirus retinitis in the era of highly active antiretroviral therapy (HAART). Am J Med Sci. 1999;317:318-335.

15. Jabs DA, Van Natta ML, Holbrook JT, et al. Longitudinal study of the ocular complications of AIDS. 1. Ocular diagnoses at enrollment. Ophthalmology. 2007;114:780-786.

16. Jabs DA, Van Natta ML, Holbrook JT, et al. Longitudinal study of the ocular complications of AIDS. 2. Ocular examination results at enrollment. Ophthalmology. 2007;114:787-793.

17. Holland GN, Vaudaux JD, Shiramizu KM, et al. Characteristics of untreated AIDS-related cytomegalovirus retinitis. II. Findings in the era of highly active antiretroviral therapy (1997 to 2000). Am J Ophthalmol. 2008;145:12-22.

18. Jabs DA, van Natta ML, Kempen JH, et al. Characteristics of patients with cytomegalovirus retinitis in the era of highly active antiretroviral therapy. Am J Ophthalmol. 2002;133:48-61.

19. Jabs DA, van Natta ML, Thorne JE, et al. Course of cytomegalovirus retinitis in the era of highly active antiretroviral therapy: 2. Second eye involvement and retinal detachment. Ophthalmology. 2004;111: 2232-2239.

20. Jabs DA, van Natta ML, Thorne JE, et al. Course of cytomegalovirus retinitis in the era of highly active antiretroviral therapy: 1 . Retinitis progression. Ophthalmology. 2004;111:2224-2231.

21. Jabs DA, Holbrook JT, van Natta ML, et al. Risk factors for mortality in patients with AIDS in the era of highly active antiretroviral therapy. Ophthalmology. 2005;112:771-779.

22. Lalezari JP, Friedberg DN, Bisset J, et al. High dose oral ganciclovir treatment for cytomegalovirus retinitis. J Clin Virol. 2002;24 $67-77$

23. Noble S, Faulds D. Ganciclovir: An update of its use in the prevention of cytomegalovirus infection and disease in transplant recipients. Drugs. 1998;56:115-146.

24. Faulds D, Heel RC. Ganciclovir: A review of its antiviral activity, pharmacokinetic properties and therapeutic efficacy in cytomegalovirus infections. Drugs. 1990;39:597-638.

25. Markham A, Faulds D. Ganciclovir: An update of its therapeutic use in cytomegalovirus infection. Drugs. 1994;48:455-484.

26. Boivin G, Gilbert C, Gaudreau A, et al. Rate of emergence of cytomegalovirus (CMV) mutations in leukocytes of patients with acquired immunodeficiency syndrome who are receiving valganciclovir as induction and maintenance therapy for CMV retinitis. $J$ Infect Dis. 2001;184:1598-1602.

27. Jabs DA, Martin BK, Forman MS, et al. Cytomegalovirus resistance to ganciclovir and clinical outcomes of patients with cytomegalovirus retinitis. Am J Ophthalmol. 2003;135:26-34.

28. Biron KK. Antiviral drugs for cytomegalovirus diseases. Antiviral Res. 2006;71:154-163.

29. Razonable RR, Emery VC. Management of CMV infection and disease in transplant patients [Consensus article IHMF management recommendations]. Herpes. 2004;11:77-86.

30. De Clerq E. Antiviral drugs in current clinical use. J Clin Virol. 2004;30:115-133.
31. Drew WL, Ives D, Lalezari JP, et al. Oral ganciclovir as maintenance treatment for cytomegalovirus retinitis in patients with AIDS. $N$ Engl J Med. 1995;333:615-620.

32. Martin DF, Kupperman BD, Wolitz RA, et al. Oral ganciclovir for patients with cytomegalovirus retinitis treated with a ganciclovir implant. N Engl J Med. 1999;340:1063-1070.

33. Brown F, Banken L, Saywell K, et al. Pharmacokinetics of valganciclovir and ganciclovir following multiple oral dosages of valganciclovir in HIV- and CMV-seropositive volunteers. Clin Pharmacokinet. 1999;37:167-176.

34. Jung D, Dorr A. Single-dose pharmacokinetics of valganciclovir in HIV-and CMV-seropositive subjects. J Clin Pharmacol. 1999;39: 800-804.

35. Henry K, Cantrill H, Fletcher C, et al. Use of intravitreal ganciclovir (dihydroxy propoxymethyl guanine) for cytomegalovirus retinitis in a patient with AIDS. Am J Ophthalmol. 1987;103:17-23.

36. Young SH, Morlet N, Henry S, et al. High dose intravitreal ganciclovir in the treatment of cytomegalovirus retinitis. Med J Aust. 1992;157: 370-373.

37. Cochereau-Massin I, Lehoang P, Lautier-Frau M, et al. Efficacy and tolerance of intravitreal ganciclovir in cytomegalovirus retinitis in acquired immune deficiency syndrome. Ophthalmology. 1991;98: 1348-1353.

38. Diaz-Llopis M, Chipont E, Sanchez, et al. Intravitreal foscarnet for cytomegalovirus retinitis in a patient with acquired immunodeficiency syndrome. Am J Ophthalmol. 1992;114:742-747.

39. Lieberman RM, Orellana J, Melton RC. Efficacy of intravitreous foscarnet in a patient with AIDS. $N$ Engl J Med. 2004;330:868-869.

40. Diaz-Llopis M, Espana E, Munoz G, et al. High dose intravitreal foscarnet in the treatment of cytomegalovirus retinitis in AIDS. $\mathrm{Br} \mathrm{J}$ Ophthalmol. 1994;78:120-124.

41. Package insert. Vistide (cidofovir, Foster City, CA: Gilead Sciences, September 1996)

42. Rahhal FM, Arevalo JF, Munguia D, et al. Intravitreal cidofovir for the maintenance treatment of cytomegalovirus retinitis. Ophthalmology. 1996;103:1078-1083.

43. Kupperman B, Wolitz R, Stagg R, et al. A Phase II randomized, double-masked study of intraocular cidofovir for relapsing cytomegalovirus retinitis in patients with AIDS [Abstract]. Presented at the Vitreous Society Annual Meeting. Cancun, Mexico, December 8-12, 1996.

44. Jabs DA. Ocular manifestations of HIV infection. Trans Am Ophthalmol Soc. 1995;93:623-683.

45. Kempen JH, Jabs DA, Wilson LA, et al. Incidence of cytomegalovirus (CMV) retinitis in second eyes of patients with the acquired immune deficiency syndrome and unilateral CMV retinitis. Am J Ophthalmol. 2005;139:1028-1034.

46. Kempen JH, Jabs DA, Wilson LA, et al. Mortality risk for patients with cytomegalovirus retinitis and acquired immune deficiency syndrome. Clin Infect Dis. 2003;37:1365-1373.

47. Jabs DA, Holbrook JT, van Natta ML, et al. Risk factors for mortality in patients with AIDS in the era of highly active antiretroviral therapy. Ophthalmology. 2005;112:771-779.

48. Musch DC, Martin DF, Gordon JF, et al. Treatment of cytomegalovirus retinitis with a sustained-release ganciclovir implant. $N$ Engl $J$ Med. 1997;337:83-90.

49. Cvetkovic RS, Wellington K. Valganciclovir: A review of its use in the management of CMV infection and disease in immunocompromised patients. Drugs. 2005;65:859-878.

50. The Studies of Ocular Complications of AIDS Research Group in collaboration with the AIDS Clinical Trials Group. Combination foscarnet and ganciclovir therapy vs monotherapy for the treatment of relapsed cytomegalovirus retinitis in patients with AIDS: The Cytomegalovirus retreatment trial. Arch Ophthalmol. 1996;114:23-33.

51. Jacobson MA. Drug therapy: treatment of cytomegalovirus retinitis in patients with the acquired immunodeficiency syndrome. $N$ Engl $\mathrm{JMed}$. 1997;337:105-114. 
52. The Studies of Ocular Complications of AIDS Research Group in collaboration with the AIDS Clinical Trials Group. The ganciclovir implant plus oral ganciclovir versus parenteral cidofovir for the treatment of cytomegalovirus retinitis in patients with acquired immunodeficiency syndrome: The ganciclovir cidofovir cytomegalovirus retinitis trial. Am J Ophthalmol. 2001;131:457-467.

53. Kupperman BD, Quiceno JI, Flores-Aguilar M, et al. Intravitreal ganciclovir concentration after intravenous administration in AIDS patients with cytomegalovirus retinitis: implications for therapy. J Infect Dis. 1993;168:1506-1509.

54. Aravelo JF, Gonzalez C, Capparelli EV, et al. Intravitreous and plasma concentrations of ganciclovir and foscarnet after intravenous therapy in patients with AIDS and cytomegalovirus retinitis. J Infect Dis. 1995;172:951-956.

55. Jabs DA, Enger C, Dunn JP, Forman M. Cytomegalovirus retinitis and viral resistance: ganciclovir resistance. CMV Retinitis and Viral Resistance Study Group. J Infect Dis. 1998;177:770-773.

56. Jabs DA, Enger C, Dunn JP, Forman M. Incidence of foscarnet resistance and cidofovir resistance in patients treated for cytomegalovirus retinitis. The Cytomegalovirus Retinitis and Viral Resistance Study Group. Antimicrob Agents Chemother. 1998;42:2240-2244.

57. Weinberg A, Jabs DA, Chou S, et al. Mutations conferring foscarnet resistance in a cohort of patients with acquired immunodeficiency syndrome and cytomegalovirus retinitis. J Infect Dis. 2003;187: 777-784.

58. Martin DF, Sierra-Madero J, Walmsley S, et al. A controlled trial of valganciclovir as induction therapy for cytomegalovirus retinitis. N Engl J Med. 2002;346:1119-1126.

59. Plosker GL, Noble S. Cidofovir: A review of its use in cytomegalovirus retinitis in patients with AIDS. Drugs. 1999;58:325-345.

60. Walmsley S, Tseng A. Comparative tolerability of therapies for cytomegalovirus therapy. Drug Saf. 1999;21:203-224.

61. Acharya N, Young L. Sustained-release drug implants for the treatment of intraocular disease. Int Ophthalmol Clin. 2004;44:33-39.

62. Jabs DA. AIDS and Ophthalmology, 2008. Arch Ophthalmol. 2008;126:1143-1146.

63. Mahadevia PJ, Gebo KA, Pettit K, et al. The epidemiology, treatment patterns, and costs of cytomegalovirus retinitis in the post-HAART era among a national managed-care population. J Acquir Immune Defic Syndr. 2004;36:972-977.

64. Walmsley SL, Raboud J, Angel JB, et al. Long-term follow-up of a cohort of HIV-infected patients who discontinued maintenance therapy for cytomegalovirus retinitis. HIV Clin Trials. 2006;7:1-9.

65. Martin BK, Ricks MO, Forman MS, Jabs DA. Change over time in incidence of ganciclovir resistance in patients with cytomegalovirus retinitis. Clin Infect Dis. 2007:44:1001-1008.

66. Benson CA, Kaplan JE, Masur H, et al. Treating opportunistic infections among HIV-infected adults and adolescents: Recommendations from CDC, the National Institutes of Health, and the HIV Medicine Association/Infectious Diseases Society of America. MMWR Recomm Rep. 2004;53:1-112.

67. Holland GN. Discussion of MacDonald JC, Karavellas MP, Torriani FJ, et al. Highly active antiretroviral therapy-related immune recovery in AIDS patients with cytomegalovirus retinitis. Ophthalmology. 2000;107:877-833.

68. Wohl DA, Kendall MA, Owens S, et al. The safety of discontinuation of maintenance therapy for cytomegalovirus (CMV) retinitis and incidence of immune recovery uveitis following potent antiretroviral therapy. HIV Clin Trials. 2005;6:136-146.

69. Jabs DA, Martin BK, Forman MS, Ricks MO. Cytomegalovirus (CMV) blood DNA load, CMV retinitis progression, and occurrence of resistant CMV in patients with CMV retinitis. J Infect Dis. 2005;192:640-649.

70. Holland GN. AIDS and Ophthalmology: The first quarter century. Am J Ophthalmol. 2008;145:397-408.

71. Skiest DJ. Cytomegalovirus retinitis in the era of highly active antiretroviral therapy (HAART). Am J Med Sci. 1999;317:318-335.
72. Kempen JH, Frick KD, Jabs DA. Incremental cost effectiveness of prophylaxis for cytomegalovirus disease in patients with AIDS. Pharmacoeconnomics. 2001;19:1199-1208.

73. Murdoch DM, Venter WD, Van Rie A, Feldman C. Immune reconstitution inflammatory syndrome (IRIS): Review of common infectious manifestations and treatment options. AIDS Research and Therapy. 2007;4:9.

74. Kempen JH, Min YI, Freeman WR, et al. Risk of immune recovery uveitis in patients with AIDS and cytomegalovirus retinitis. Ophthalmology. 2006;113:684-694.

75. Hirsch HH, Kaufmann G, Sendi P, et al. Immune reconstitution in HIV infected patients. Clin Infect Dis. 2004;38:1159-1166.

76. Thorne JE, Jabs DA, Kempen JH, et al. Incidence of and risk factors for visual acuity loss among patients with AIDS and cytomegalovirus retinitis in the era of highly active antiretroviral therapy. Ophthalmology. 2006;113:1423-1440.

77. French MA. The immunopathogenesis of mycobacterial immune restoration disease. Lancet Infect Dis. 2006;6:461-462.

78. Karavellas MP, Plummer DJ, MacDonald JC, et al. Incidence of immune recovery vitritis in cytomegalovirus retinitis patients following institution of successful highly active antiretroviral therapy. J Infectious Dis. 1999;179:697-700

79. Kempen JH, Min YI, Freeman WR, et al. Risk of immunity recovery uveitis in patients with AIDS and cytomegalovirus retinitis. Ophthalmology. 2006;113:684-694.

80. Schrier RD, Song MK, Smith IL, et al. Intraocular viral and immune pathogenesis of immune recovery uveitis in patients with healed cytomegalovirus retinitis. Retina. 2006;26:165-169.

81. Westeneg AC, Rothova A, De Boer JH, Groot-Mijnes JD. Infectious uveitis in immunocompromised patients and the diagnostic value of polymerase chain reaction and Goldmann-Witmer coefficient in aqueous analysis. Am J Ophthalmol. 2007;144:781-785.

82. Ortega-Larrocea G, Espinosa E, Reyes-Teran G. Lower incidence and severity of cytomegalovirus-associated immune recovery uveitis in HIV-infected patients with delayed highly active antiretroviral therapy. AIDS. 2005;19:735-738.

83. Henderson HW, Mitchell SM. Treatment of immune recovery vitritis with local steroids. Br J Ophthalmol. 1999;83:540-545.

84. Karavellas MP, Azen SP, Macdonald C, et al. Immune recovery uveitis and uveitis in AIDS: Clinical predictors, sequellae and treatment outcome. Retina. 2001;21:1-9.

85. El-Bradey M, Cheng L, Song M, et al. Long term results of treatment of macular complications in eyes with immune recovery uveitis using a graded treatment approach. Retina. 2004;24:376-382.

86. Henderson HW, Mitchell SM. Treatment of immune recovery vitritis with local steroids. Br J Ophthalmol. 1999;83:540-545.

87. Rothova A. Inflammatory cystoid macular oedema. Current Opinion Ophthalmol. 2007;18:487-492.

88. Ufret-Vincenty RL, Singh RP, Lowder CY, Kaiser PK. Cytomegalovirus retinitis after fluocinolone acetonide implant. Am J Ophthalmol. 2007;143:334-335.

89. Morrison VL, Kozak I, LaBree LD, et al. Intravitreal triamcinolone acetonide for the treatment of immune recovery uveitis macular edema. Ophthalmology. 2007;114:334-339.

90. Canzano JC, Morse LS, Wendel RT. Surgical repair of cytomegalovirusrelated retinal detachment without silicone oil in patients with AIDS. Retina. 1999;19:274-280.

91. Davis J. Removing silicone oil from eyes with cytomegalovirus retinitis. Am J Ophthalmol. 2005;140:900-902.

92. Kestelyn P. The epidemiology of CMV retinitis in Africa. Ocul Immunol Inflamm. 1999;7:173-177.

93. Shah SU, Kerkar SP, Pazare AR. Evaluation of ocular manifestations and blindness in HIV/AIDS patients on HAART in a tertiary care hospital in western India. Br J Ophthalmol. 2009;93:88-90.

94. Gharai S, Venkatesh P, Garg S, et al. Ophthalmic manifestations of HIV infections in India in the era of HAART: Analysis of 100 consecutive patients evaluated at a tertiary eye care center in India. Ophthalmic Epidemiol. 2008;15(4):264-271. 
95. Biswas J, Madhavan HN, George AE, et al. Ocular lesions associated with HIV infection in India: A series of 100 consecutive patients evaluated at a referral center. Am J Ophthalmol. 2000;129:9-15.

96. Biswas PN, Saha B, Ghosh S, et al. Ophthalmic manifestations in people living with HIV attending a tertiary care centre of Eastern India. J Indian Med Assoc. 2008;106:292-294.

97. Nkomazana O, Tshitswana D. Ocular complications of HIV infection in sub-Sahara Africa. Curr HIV/AIDS Rep. 2008;5:120-125.

98. Nwosu NN. HIV/AIDS in ophthalmic patients: The Guinness Eye Centre Onitsha experience. Niger Postgrad Med J. 2008;15:24-27.

99. T/Giorgis A, Melka, G/Mariam A. Ophthalmic manifestation of aids in Armed Forces General Teaching Hospital, Addis Ababa. Ethiop Med J. 2007;45:327-334.

100. Osahon Al, Onunu AN. Ocular disorders in patients infected with the human immunodeficiency virus at the University of Benin Teaching Hospital, Benin City, Nigeria. Niger J Clin Pract. 2007;10(4):283-286.

101. Manosuthi W, Chaovavanich A, Tansuphaswakiful S, et al. Incidence and risk factors of major opportunistic infections after initiation of antiretroviral therapy among advanced HIV-infected patients in a resource-limited setting. J Infect. 2007;55:464-469.

102. Shafran SD, Singer J, Zarowny DP, et al. A comparison of two regimens for the treatment of Mycobacterium avium complex bacteremia in AIDS: Rifabutin, ethambutol, and clarithromycin versus rifampin, ethambutol, clofazimine, and ciprofloxacin. Canadian HIV Trials Network Protocol 010 Study Group. N Engl J Med. 1996;335:377-383.

103. Nichols CW. Mycobacterium avium complex infection, rifabutin, and uveitis - is there a connection? Clin Infect Dis. 1996;22:S43-S47.
104. Cochereau I, Mlika-Cabanne N, Godinaud P, et al. AIDS related eye disease in Burundi, Africa. Br J Ophthalmol. 1999;83:339-342.

105. Weng TN, Versace P. Ocular association of HIV infection in the era of highly active antiretroviral therapy and the global perspective. Clin Exp Ophthalmol. 2005;33:317-329.

106. Ausayakhun S, Watananiforn S, Ngamtiphakorn S, Prasitsilp J. Intravitreal foscarnet for cytomegalovirus retinitis in patients with AIDS. J Med Assoc Thai. 2005;88:103-107.

107. Teerawattananon K, Iewsakul S, Yenjitr C, et al. Economic evaluation of treatment administration strategies of ganciclovir for cytomegalovirus retinitis in HIV/AIDS patients in Thailand: a simulation study. Pharmacoeconomics. 2007;25:413-428.

108. Chiou SH, Liu CY, Hsu WM, et al. Ophthalmic findings in patients with acquired immunodeficiency syndrome. J Microbiol Immunol Infect. 2000;33:45-48.

109. DeCock KM, Lucas SB, Lucas S, et al. Clinical research, prophylaxis, therapy, and care for HIV disease in Africa. Am J Public Health. 1993;83:1385-1389.

110. National AIDS Control Organization, Ministry of Health and Family Welfare, Government of India. Programme implementation guidelines for phased scale up of access to antiretroviral therapy for people living with HIV/AIDS. Mumbai, India: National AIDS Control Organization; 2004.

111. Braitstein P, Brinkhof MW, Dabis F, et al. Mortality of HIV-1infected patients in the first year of antiretroviral therapy: comparison between low-income and high-income countries. Lancet. 2006;367: $817-824$
Clinical Ophthalmology

\section{Publish your work in this journal}

Clinical Ophthalmology is an international, peer-reviewed journa covering all subspecialties within ophthalmology. Key topics include: Optometry; Visual science; Pharmacology and drug therapy in eye diseases; Basic Sciences; Primary and Secondary eye care; Patien Safety and Quality of Care Improvements. This journal is indexed on

Submit your manuscript here: http://www.dovepress.com/clinical-ophthalmology-journal

\section{Dovepress}

PubMed Central and CAS, and is the official journal of The Society of Clinical Ophthalmology (SCO). The manuscript management system is completely online and includes a very quick and fair peer-review system, which is all easy to use. Visit http://www.dovepress.com/ testimonials.php to read real quotes from published authors. 